\title{
Inhalation of inactivated-Mycobacterium phlei prevents asthma-mediated airway hyperresponsiveness and airway eosinophilia in mice by reducing IL-5 and IL-13 levels
}

\author{
MOYU MING, ZHIXI LUO, SHENGQIU LV and CHAOQIAN LI \\ Department of Respiratory Medicine, The First Affiliated Hospital of Guangxi Medical University, \\ Nanning, Guangxi 530021, P.R. China
}

Received September 29, 2015; Accepted October 4, 2016

DOI: $10.3892 / \mathrm{mmr} .2016 .5865$

\begin{abstract}
The present study aimed to investigate whether inhalation of inactivated-Mycobacterium phlei could prevent airway hyperresponsiveness and airway eosinophilia. A total of 24 male Balb/c mice were randomly divided into three groups: Normal control group (group A), asthma model group (group B) and the intervention group (group C), (8 mice/group). Group A mice were sensitized and with challenged saline and group B with ovalbumin (OVA). Group C mice were administered with aerosol Mycobacterium phlei once daily prior to the allergen challenge. Airway responsiveness in each group was assessed. All the animals were sacrificed and lung tissues, blood samples and bronchoalveolar lavage fluid (BALF) were harvested. Cell fractionation and differential cells were counted in serum and BALF. HE staining and alcian blue/periodic acid Schiff staining were used to measure airway eosinophilic inflammation and mucus production. The levels of the cytokines IL-5, IL-13 and IgE were measured in lung and BALF as determined by ELISA and reverse transcription-quantitative polymerase chain reaction assays. The results indicated that inactivated-Mycobacterium phlei suppressed the airway hyperresponsiveness and mitigated airway eosinophilia induced by a methacholine challenge, and significantly reduced the levels of cytokines IL-5 and IL-13 in lung tissue and IgE level in BALF when compared with the OVA-sensitized mice. In conclusion, inhalation of inactivated-Mycobacterium phlei could reduce OVA-induced airway hyperresponsiveness and may be a potential alternative therapy for allergic airway diseases.
\end{abstract}

Correspondence to: Professor Chaoqian Li, Department of Respiratory Medicine, The First Affiliated Hospital of Guangxi Medical University, 6 Shuangyong Road, Qingxiu, Nanning, Guangxi 530021, P.R. China

E-mail: chaoqianli123456@163.com

Key words: airway eosinophilia, airway hyperresponsiveness, IL-5, IL-13, immunoglobulin E, immunotherapy, Mycobacterium, inhalation

\section{Introduction}

An estimated 300 million patients suffer from asthma worldwide (1). Allergic asthma is a T-helper 2 (Th2) lymphocyte-mediated inflammatory airway disease, and airway hyperresponsiveness (AHR) is a key part of the definition of asthma, and is one of the key features underpinning periodic bronchoconstriction (2). AHR is characterized by exaggerated airway narrowing subsequent to exposure to nonspecific stimuli including methacholine $(\mathrm{MCh})$, histamine and exercise, or allergens including certain respiratory viruses, certain organic chemicals or pollutants (3). The degree of AHR is usually in proportion to the severity of the underlying asthma (4). The requirements for asthma medication include improving airflow limitations, reducing symptoms and modifying underlying AHR.

Classical Th2 cell-derived cytokines, particularly, interleukin (IL)-5 and IL-13 serve a pivotal role in the pathogenesis of asthma via eotaxin to regulate eosinophilia (5). IL-5 delays eosinophil apoptotic death, promotes eosinophil adhesion activity and enhances eosinophil effector function (6). Blocking IL-5 has been previously identified to inhibit eosinophil influx into the airways in addition to suppressing AHR (7). IL-13 shares several biological responses with IL-4 and may also be important in the development of allergic airway eosinophilia and AHR $(8,9)$. IL-13 serves a regulatory role in Th2 activation (10) and is a key mediator in asthma, including switching plasma cell antibody synthesis from immunoglobulin (Ig)M to $\mathrm{IgE}$ production (11), promoting eosinophil migration into the lungs (12), upregulating adhesion molecules (13), increasing goblet cell hyperplasia and mucus production (14), increasing proliferation of airway smooth muscle (15), stimulating airways hyperresponsiveness (16). IL-13 blockade inhibited airway inflammation, hyperresponsiveness and remodeling (17).

It is widely accepted that exposure to pathogens can elicit protective effects, potentially through activation of innate immune responses. The hygiene hypothesis states that early exposure to pathogens provides protective effects against asthma and the prevalence of allergies, which is suggested to be as a result of alterations in environmental factors including reduced exposure to microbial antigens during infancy. Therefore, the impact of microbes and bacterial extracts on 
respiratory allergies have been investigated in mouse asthma models and in humans (18-20). Additional studies have examined the effects of mycobacterial infection including Mycobacterium tuberculosis and mycobacteria other than tuberculosis on asthma (21).

Previous studies demonstrated that the Bacillus Calmette-Guérin (BCG) vaccine can prevent the formation of a rat asthmatic model and inhalation of inactivated-Mycobacterium phlei can restore the balance of the immune system and attenuate airway inflammation in a murine model of asthma (22,23). However, the effects of inhaled inactivated-Mycobacterium phlei on AHR in a mice model of asthma remain unclear. In the current study, the effect of inactivated-Mycobacterium phlei on airway response to MCh was investigated in a murine model of ovalbumin (OVA)-induced allergic asthma.

\section{Materials and methods}

Animals. Male pathogen-free Balb/c mice (4-6 weeks old; weight, 20-24 g) were obtained from the Laboratory Animal Center of Guangxi Medical University (Nanning, China). The mice were housed under specific-pathogen-free conditions in a facility with an automatic $12 / 12 \mathrm{~h}$ day and night cycle and fed with standard laboratory food and water ad libitum. All experimental animals were used in accordance with the guidelines issued by the Chinese Council on Animal Care. The study was approved by the ethics committee of Guangxi Medical University (Nanning, China).

Sensitization, allergen exposure and treatment. Mice were randomly categorized into three experimental groups and each group consisted of 8 mice: The normal control group (group A), the asthma model group (group B) and the intervention group (group C). In groups B and C, the mice were repeatedly sensitized and challenged with OVA (grade V; Sigma-Aldrich; Merck Millipore; Darmstadt, Germany) to establish a murine asthma model according to the method described in a previous study (23). In brief, mice were sensitized by intraperitoneal injection of $25 \mu \mathrm{g}$ OVA emulsified in $1 \mathrm{mg} \mathrm{Al}(\mathrm{OH})_{3}$ (Chengdu Kelong Chemical Reagent Factory, Chengdu, China) suspended in $0.2 \mathrm{ml}$ saline on days 0,7 and 14 . Following sensitization, the mice were challenged for 20 min with $2 \%$ OVA once daily by an ultrasonic nebulizer (WH-2000; Guangdong YueHua Medical Instrument Factory Co., Ltd., Guangzhou, China) in a closed chamber from days 21-28. Mice in group $\mathrm{C}$ inhaled the solution of inactivated Mycobacterium phlei (each ampoule contained $1.72 \mu \mathrm{g}$ Mycobacterium phlei dissolved in $10 \mathrm{ml}$ saline) using a nebulizer once daily prior to each challenge. The normal group and model group were sham-treated with $10 \mathrm{ml}$ saline atomization. Lung resistance $\left(\mathrm{R}_{\mathrm{L}}\right)$ was assessed $24 \mathrm{~h}$ subsequent to the last inactivated-Mycobacterium phlei treatment or saline treatment and then the mice were intraperitoneally anesthetized with $10 \%$ chloral hydrate $(0.3 \mathrm{ml} / 100 \mathrm{~g}$; Dalian Meilun Biological Technology Co., Ltd., Dalian, China) and sacrificed by cervical dislocation under anesthesia.

Measurement of AHR to MCh. Respiratory resistance $\left(\mathrm{R}_{\mathrm{L}}\right.$, $\mathrm{cmH}_{2} \mathrm{O} . \mathrm{s} / \mathrm{ml}$ ) was determined as changes in the airway function subsequent to inhalation of MCh challenge (24).
Respiratory resistance was assessed in anesthetized and tracheotomized mice that were mechanically ventilated in response to an increasing concentration of $\mathrm{MCh}$ inhalation using the pulmonary function equipment from the RC System for Mouse (Buxco Research Systems, Wilmington, NC, USA).

Preparation of bronchoalveolar lavage fluid (BALF). Subsequent to assessment of the respiratory mechanics, the mice were anesthetized with chloral hydrate $(400 \mathrm{mg} / \mathrm{kg}$ intraperitoneal injection). The trachea was immediately exposed and carefully cannulated with a 24-gauge-feeding needle. The catheter was secured with ligatures. Pre-warmed phosphate-buffered saline (PBS) solution (at $37^{\circ} \mathrm{C}$ ) was slowly infused into the lungs and withdrawn gently, and this was repeated three times. The BALF was collected and maintained at $4^{\circ} \mathrm{C}$.

Cell fractionation and differential cell count in serum and $B A L F$. Blood samples for serum were collected from the orbital artery. The BALF was centrifuged at $300 \mathrm{x} g$ for $2 \mathrm{~min}$ at $4^{\circ} \mathrm{C}$. Cell pellets were resuspended in $100 \mu \mathrm{l}$ PBS. Total cell numbers in BALF were measured using a haemacytometer. Smears of blood samples and BALF cells were prepared using a cytospin. A differential cell count was performed using Wright-Giemsa following the manufacturer's instructions to classify eosinophils on the basis of morphological criteria and staining characteristics. Differential cell counts were made blind on 100 cells/slide under an oil lens at a magnification of $\mathrm{x} 100$.

Histological analysis of lung tissue. Lungs were isolated from the mice subsequent to BALF, fixed with $10 \%$ formalin for $24 \mathrm{~h}$, and embedded in paraffin. Specimens were cut into $4-\mu \mathrm{m}$ sections. The microsections were stained with hematoxylin-eosin (HE) and alcian blue/periodic acid Schiff (AB-PAS) to analyze inflammatory cell infiltration and mucus production, respectively.

Enzyme-linked immunosorbent assay (ELISA) for IgE, IL-5 and IL-13 in BALF. Levels of IgE, IL-5 and IL-13 in BALF were measured by ELISA (R\&D Systems, Inc., Minneapolis, MN, USA). The absorbance was measured at $450 \mathrm{~nm}$ using a microplate ELISA reader (Bio-Rad Laboratories, Inc., Hercules, CA, USA).

Reverse transcription-quantative polymerase chain reaction (RT-qPCR) for IL-5 and IL-13. Total RNA was isolated from lung tissues using TRIzol reagent according to the manufacturer's protocol (Invitrogen; Thermo Fisher Scientific, Inc., Waltham, MA, USA) and was quantified with the Nanodrop 2000 spectrophotometer (Thermo Fisher Scientific, Inc.). A total of $2 \mu \mathrm{g}$ target RNA was reverse transcribed into cDNA using RevertAid ${ }^{\mathrm{TM}}$ First Strand cDNA Synthesis kit (Fermentas; Thermo Fisher Scientific, Inc.) at $42^{\circ} \mathrm{C}$ for $60 \mathrm{~min}$ and $70^{\circ} \mathrm{C}$ for $5 \mathrm{~min}$. RT-qPCR was performed for IL-5, IL-13 mRNA using the ABI Prism 7500 Sequence detector (Applied Biosystems; Thermo Fisher Scientific, Inc.). The cycling conditions for PCR were as follows: $94^{\circ} \mathrm{C}$ for $5 \mathrm{~min}$, followed by 40 cycles of $94^{\circ} \mathrm{C}$ for $30 \mathrm{sec}, 59^{\circ} \mathrm{C}$ for $30 \mathrm{sec}, 72^{\circ} \mathrm{C}$ for $30 \mathrm{sec}$, then final elongation at $72^{\circ} \mathrm{C}$ for $5 \mathrm{~min}$ and held at $10^{\circ} \mathrm{C}$. The primers were designed by Takara Bio, Inc. (Otsu, 
A

\section{Group A}

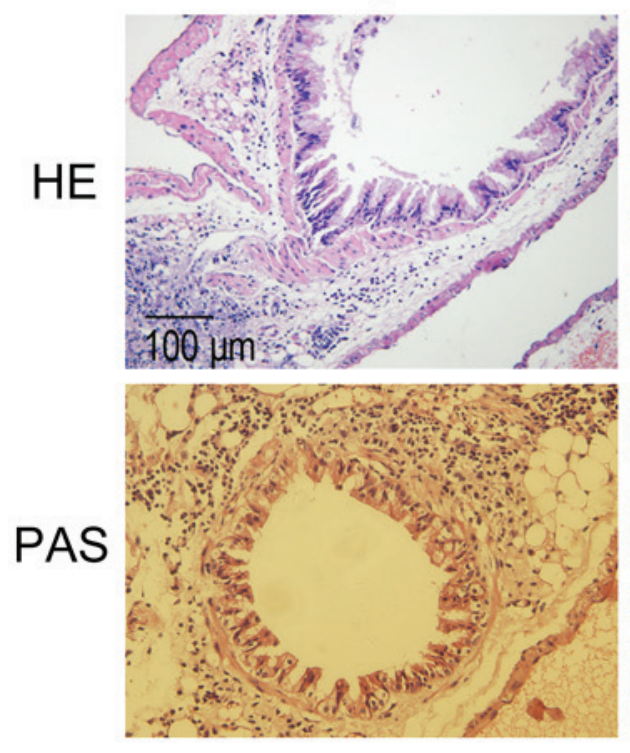

Group B

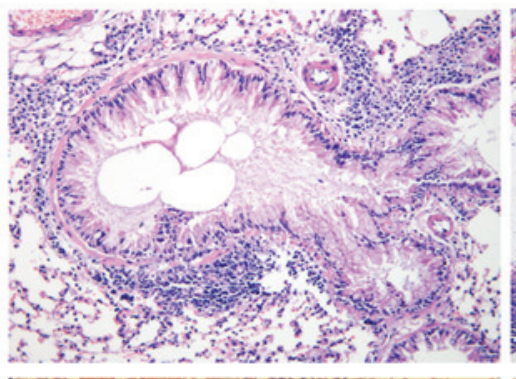

Group C
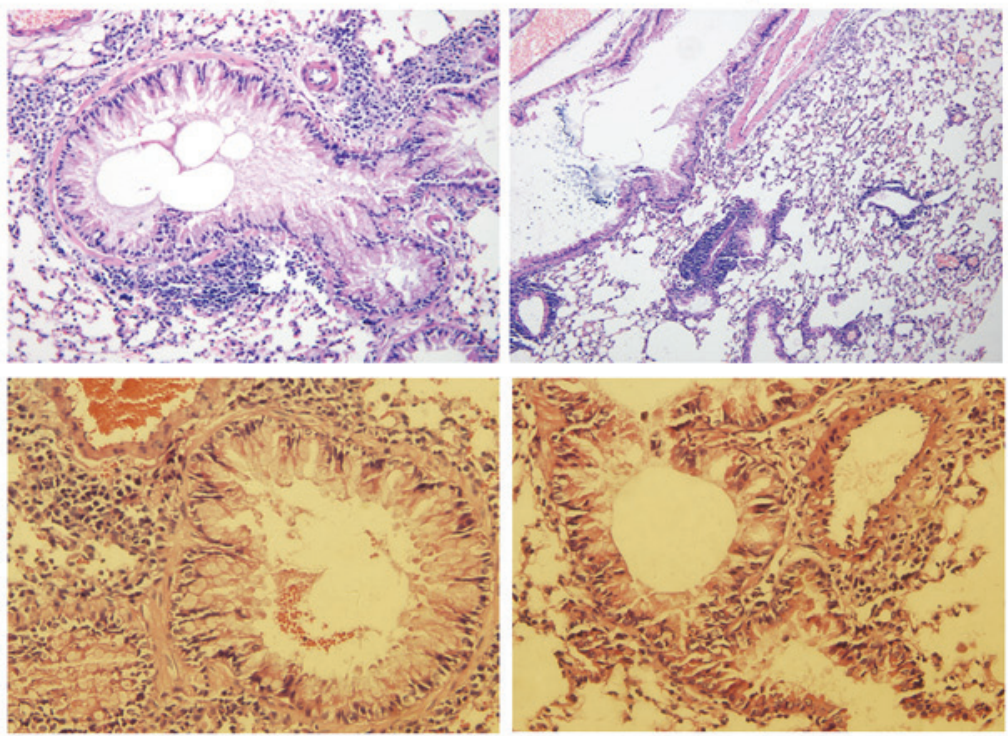

$\mathbf{B}$
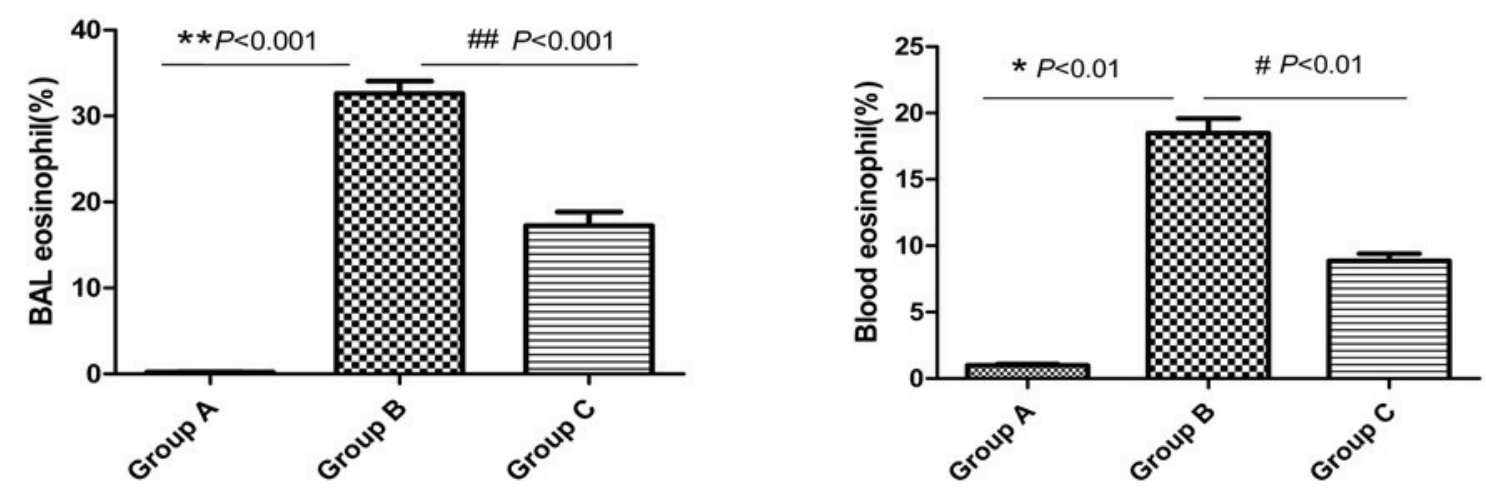

Figure 1. Comparation of airway inflammatory and eosinophilia ratios in BALF and blood in three groups. The OVA-induced airway inflammatory was attenuated in the inactivated-Mycobacterium phlei prevention group. Group A were sensitized and with challenged saline and group B with OVA. Mice in group C were pretreated with inactivated-Mycobacterium phlei prior to challenge with OVA. A total of $24 \mathrm{~h}$ after the final challenge, the eosinophilia ratio in blood and the airway was assessed. (A) Lung tissues from three groups were stained with HE and PAS. Original magnification, $x 400$. (B) Eosinophilia ratio in the three groups. Data are presented as the mean \pm standard deviation. ${ }^{*} \mathrm{P}<0.01$ and ${ }^{* *} \mathrm{P}<0.001$ vs. group $\mathrm{A} ;{ }^{\#} \mathrm{P}<0.01$ and ${ }^{\# \#} \mathrm{P}<0.001$ vs. group $\mathrm{B}$. BALF, bronchoalveolar lavage fluid; OVA, ovalbumin; HE, hematoxylin-eosin; PAS, periodic acid Schiff.

Japan) and were as follows: IL-5, forward 5'-TGAGGCTTC CTGTCCCTACTCATAA-3' and reverse 5'-TTGGAATAG CATTTCCACAGTACCC-3'; IL-13, forward 5'-CGGCAG CATGGTATGGAG-3' and reverse 5'-ATTGCAATTGGA GATGTTGGTCAG-3'.

Statistical analysis. Data are expressed as the mean \pm standard deviation. One-way analysis of variance was used for the normal control group, the asthma model group and the intervention group. $\mathrm{P}<0.05$ was considered to indicate a statistically significant difference.

\section{Results}

Inhalation of inactivated Mycobacterium phlei attenuates OVA-induced pulmonary pathologies and inhibits airway and blood eosinophilia. Mice in the normal control group (group A) were observed with HE staining to exhibit normal lung tissue structures, with no inflammatory cells (Fig. 1A). In the asthma model group (group B), mice challenged with OVA exhibited a significant infiltration of inflammatory cells around the airways and blood vessels (HE; Fig. 1A). In addition, the majority of the infiltrated inflammatory cells were eosinophils (Fig. 1B). Compared with group A, there was increased goblet cell hyperplasia in the airway epithelia and increased thickened basement membranes in group B (PAS; Fig. 1A). The administration of inactivated Mycobacterium phlei reduced the infiltration of inflammatory cells (airway and blood eosinophilia) and mucus production in the peribronchial and perivascular areas compared with the asthma model mice (Fig. 1).

Inactivated Mycobacterium phlei suppresses AHR. In order to test the effects of inactivated Mycobacterium phlei on AHR, mice were sensitized and challenged with OVA. As hypothesized, inhalation of inactivated-Mycobacterium phlei prior to each challenge could suppress AHR, or potentially completely prevent AHR. At the same time, 
inactivated-Mycobacterium phlei could improve airway compliance (Fig. 2).

Reduced IgE, IL-5 and IL-13 levels in BALF following inactivated Mycobacterium phlei administration. The levels of IgE, IL-5 and IL-13 in BALF were measured. High levels of IgE, IL-5 and IL-13 were present in the asthma model group. Administration of inactivated-Mycobacterium phlei significantly $(\mathrm{P}<0.05)$ inhibited the levels of IL-5, IL-13 and IgE in BALF in group C (Fig. 3).

Inactivated-Mycobacterium phlei reduced $I L-5$ and $I L-13$ $m R N A$ expression in the lung. mRNA expression was normalized to the housekeeping gene ( $\beta$-actin). mRNA levels of IL-5 and IL-13 in lung tissue were markedly increased by induction with OVA $(\mathrm{P}<0.01)$. However, subsequent to inhalation administration of inactivated Mycobacterium phlei, the mRNA levels of the above cytokines were significantly reduced in group $\mathrm{C}(\mathrm{P}<0.05$; Fig. 4).

\section{Discussion}

The study examined the effects of inactived Mycobacterium phlei and the inhalation route of administration in OVA-sensitized mice. While evidence suggests that direct, local delivery of mycobacterial antigens is superior to systemic delivery in suppressing allergic responses in the murine model (25).

There are numerous potential factors contributing to the excessive airway response. An association between peripheral blood eosinophil activation and AHR in asthma has also been demonstrated $(26,27)$. Asthma is characterized by high levels of IgE and dominant Th2 cytokines including IL-4, IL-5 and IL-13. A previous study reported the association between eosinophil and airway structural alterations including airway remodeling, impaired forced expiratory volume after one second (FEV1) and FEV1/forced vital capacity ratio in patients with rhinitis (28). IL-5 has been previously demonstrated to serve significant roles in allergic diseases that affect various organs including the airways, such as asthma (6,29). IL-5 has been observed to regulate growth, differentiation, activation and survival of eosinophils and appears to be essential in the development of allergic airway eosinophilia and AHR in mice (30-32).

IL-13 has been demonstrated as a key regulator in IgE synthesis, mucus hypersecretion and AHR $(33,34)$. It is notable that patients with refractory eosinophilic asthma and prednisone-dependent asthma with sputum eosinophilia appear to be particularly sensitive to biological therapy for asthma, including anti-IL-5, anti-IL-13 and anti-IgE (35-38). Anti-IL-13 treatment both via the intraperitoneal and intranasal routes has been previously identified to significantly inhibit AHR in OVA-allergic animals (39).

Previously, it was reported that humanized monoclonal antibodies (mAb) against IL-5 (mepolizumab) $(35,40)$, are effective and can be used to reduce the frequency of severe exacerbations, and improve the quality of life in patients with severe refractory eosinophilic asthma. However, there have additionally been contradictory reports, suggesting that treatment with $\mathrm{mAb}$ against IL-5 had no effect on the reversal of established AHR $(41,42)$.
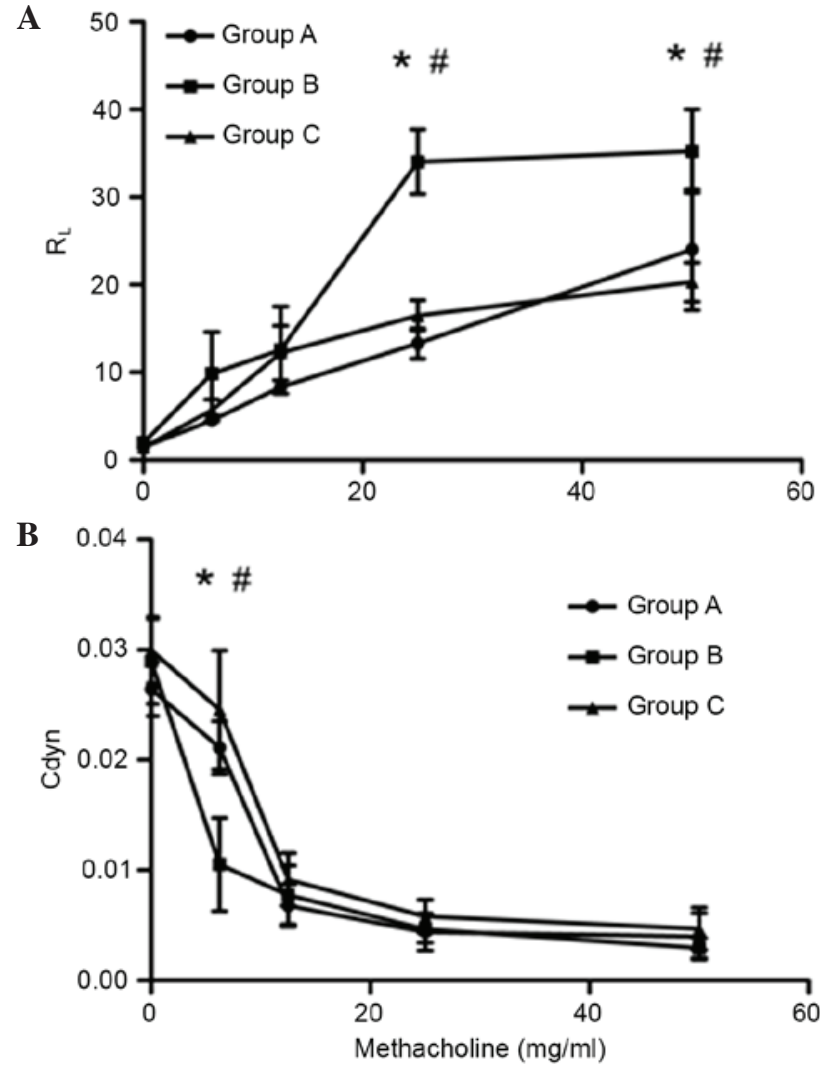

Figure 2. Airway resistance and airway compliance were compared in the three groups. Mice in three groups were assayed for (A) airway resistance and (B) airway compliance in response to various concentrations of methacholine. In the inactivated-Mycobacterium phlei prevention group (group C), airway resistance was reduced and airway compliance was increased. Data are presented as the mean \pm standard deviation. ${ }^{*} \mathrm{P}<0.05$ group $\mathrm{B}$ vs. group $\mathrm{A}$; ${ }^{\#} \mathrm{P}<0.05$ group $\mathrm{C}$ vs. group $\mathrm{B} . \mathrm{R}_{\mathrm{L}}$, pulmonary resistance; Cdyn, dynamic compliance.

The BCG vaccine is used in tuberculosis prevention and is a strong inducer of a Th1-type immune response (43). The potential benefits of BCG and mycobacteria other than tuberculosis on asthma have been previously hypothesized (44). In experimental allergic asthma, inhaled inactived-Mycobacterium phlei led to a reduction of inflammatory scores in the airways, a reduction in the levels of the Th2 cytokine IL-4, and an increase in the levels of Th1 cytokines IFN- $\gamma$ and IL-10 in BALF (23).

The results on BALF eosinophilia correlate well with the observations reported by Hopfenspirger et al (45) who conducted a similar study indicating a negative correlation between Mycobacterium and BALF eosinophilia in OVA-sensitized and challenged mice. The reduction in eosinophil percentages observed in the current study in group $\mathrm{C}$ is similar to the outcome of the effect of anti-IL-5 therapy (mepolizumab and reslizumab) when used in patients with eosinophilic esophagitis $(46,47)$ and eosinophilic asthma (48). While the exact mechanisms involved remain unclear, with further research required in order to elucidate whether the medication is able to block eosinophil production in the bone marrow or/and their removal from the circulation, the effect of inactived-Mycobacterium phlei on the eosinophils residing in the target organ is considered notable. 
A

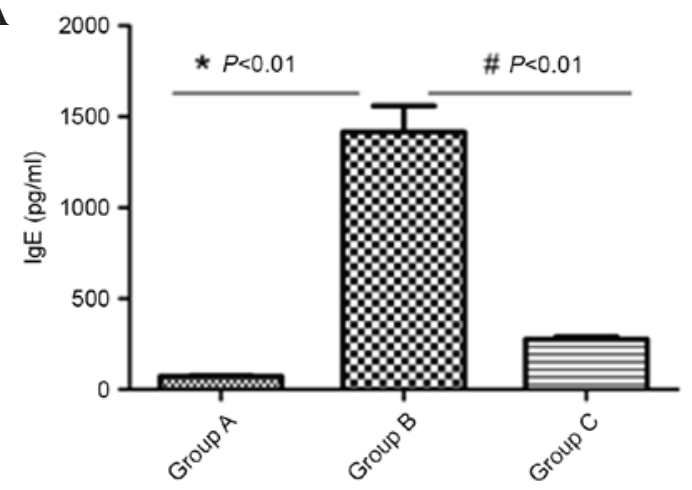

B

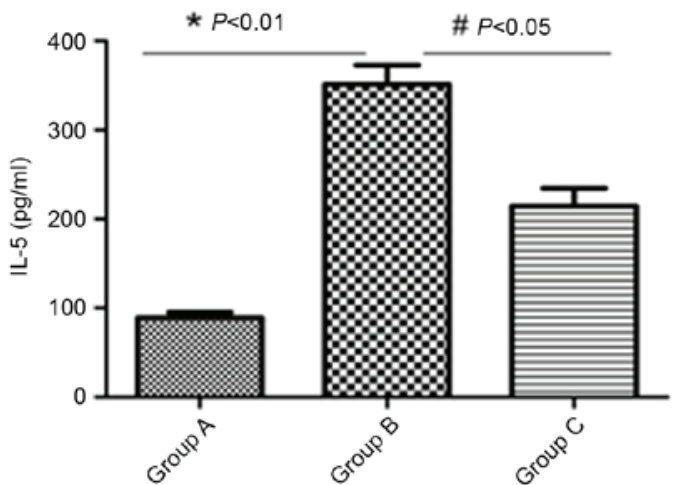

C

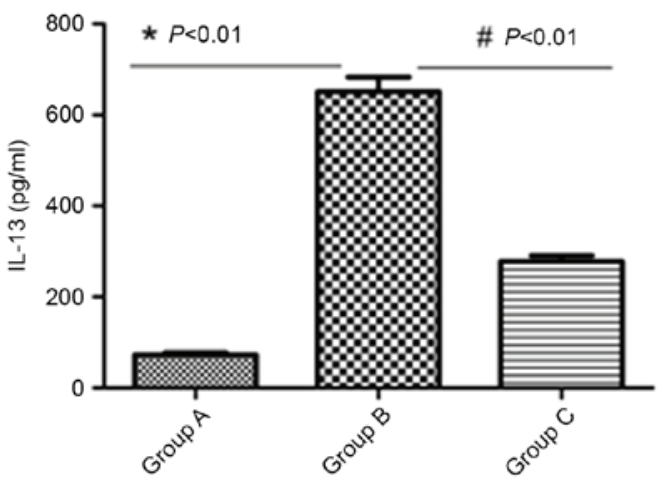

Figure 3. IgE, IL-5 and IL-13 levels in BALF were assayed with ELISA and compared in the three groups. (A) IgE, (B) IL-5 and (C) IL-13 production was reduced in group C. The BALF of mice in the three groups were assayed for IgE, IL-5 and IL-13 by ELISA. Data are presented as the mean \pm standard deviation. ${ }^{*} \mathrm{P}<0.05$ group $\mathrm{B}$ vs. group $\mathrm{A} ;{ }^{*} \mathrm{P}<0.05$ group $\mathrm{C}$ vs. group B. IgE, immunoglobulin E; IL, interleukin; BALF, bronchoalveolar lavage fluid.

The mechanism of action of inactivated Mycobacterium phlei remains unclear. It is suggested that the inhibitory effects of inactivated-Mycobacterium phlei on eosinophil infiltration are due to the inhibition of proinflammatory cytokine release, due to the fact that inactivated Mycobacterium phlei treatments did markedly modify the increased expression of IL-5 and IL-13 mRNA in lung tissue and the level of IL-5 and IL-13 in BALF induced by antigens (Figs. 3 and 4). Although the mechanism of action of inactivated-Mycobacterium phlei remains unclear, its effect on Toll-like receptors may be involved. Toll-like receptors (TLRs) are a family of triggers of the innate and adaptive immune responses against invading pathogens (49). TLR2 has been suggested to be involved in recognition of Mycobacterium tuberculosis $(50,51)$ and to be
A

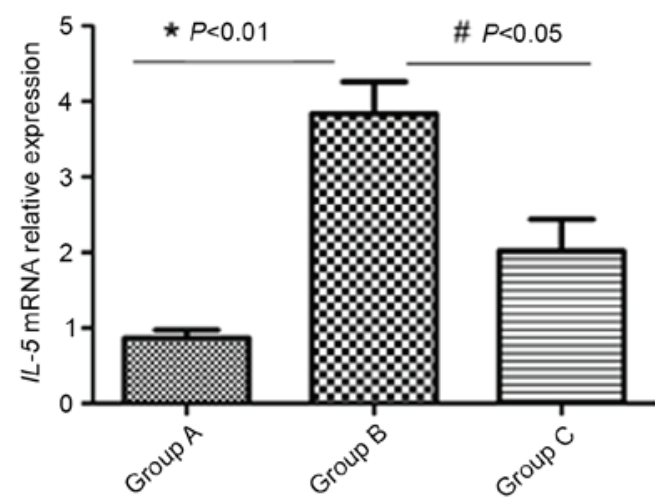

B

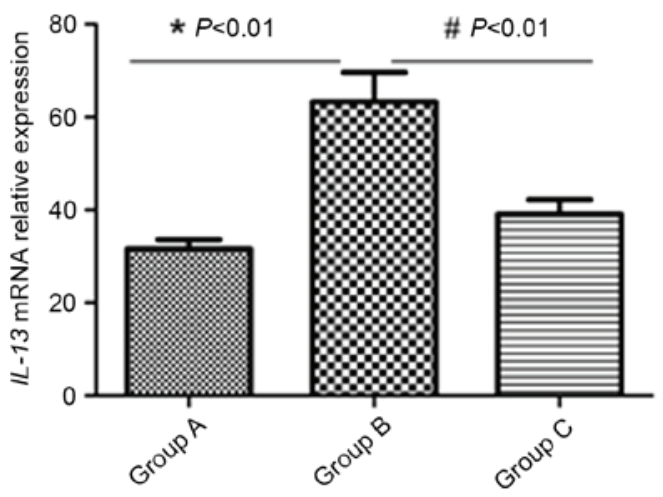

Figure 4. IL-5 mRNA and IL-13 mRNA expression in lungs were assayed using RT-qPCR and compared in the three groups. (A) IL-5 mRNA and (B) IL-13 mRNA expression were reduced in group C. The lungs of mice in the three groups were assayed for IL- 5 and IL-13 by RT-qPCR. Data are presented as the mean \pm standard deviation. ${ }^{*} \mathrm{P}<0.01$ group $\mathrm{B}$ vs. group $\mathrm{A}$; ${ }^{\#} \mathrm{P}<0.05$ group $\mathrm{C}$ vs. group B. IL, interleukin; RT-qPCR, reverse transcription-quantitative polymerase chain reaction.

important in the initiation of innate host defense through its stimulatory effects on tumor necrosis factor $\alpha$ production (52). TLR2, in particular, has been implicated in the downregulation or deviation of the immune response through the induction of IL-10 and Th2 cells or regulatory $\mathrm{T}$ cell responses, $\operatorname{IgE}$ production and eosinophil infiltration in the lung $(53,54)$. A previous study demonstrated that the level of TLR2 mRNA in the lungs was increased subsequent to treatment with inhaled inactivated-Mycobacterium phlei compared with the OVA-induced asthmatic mice (23).

In addition to the current study, previous studies have demonstrated a suppressive effect on various parameters of allergic inflammation in mouse models following mycobacteria pretreatment $(23,25,55)$. However, excluding one study by Zhang et al (23), there is no information regarding the atomization route of administration for inactivated-Mycobacterium phlei in the attenuation of airway inflammation. Hopfenspirger and Agrawal (25) observed that Mycobacterium administration via nasal injection was the most effective in attenuating allergic airway inflammation and AHR. Systemic immunization, even with adjuvants, has been observed to induce weak adaptive immune responses in the airways, while intranasal immunization elicits systemic and mucosal responses (56-58). Takabayashi et al (59) reported that intranasal immunotherapy was more effective than intradermal immunotherapy. Similarly, the results of the current 
study suggested that modulation of the airways rather than systemic immunity may be an important therapeutic target.

In conclusion, the present study demonstrated that inhalation of inactivated-Mycobacterium phlei prior to each allergen challenge inhibited AHR, in addition to reducing IL-5 and IL-13 mNRA expression in lung tissues of asthmatic mice. These inhibitory effects of inhaled inactivated-Mycobacterium phlei may be beneficial for the prevention of allergic bronchial asthma.

\section{Acknowledgements}

The current study was funded by the National Natural Science Foundation of China (grant no. 81360007).

\section{References}

1. Krishnan V, Diette GB, Rand CS, Bilderback AL, Merriman B, Hansel NN and Krishnan JA: Mortality in patients hospitalized for asthma exacerbations in the United States. Am J Respir Crit Care Med 174: 633-638, 2006.

2. Bateman ED, Hurd SS, Barnes PJ, Bousquet J, Drazen JM, FitzGerald M, Gibson P, Ohta K, O'Byrne P, Pedersen SE, et al: Global strategy for asthma management and prevention: GINA executive summary. Eur Respir J 31: 143-178, 2008.

3. Taube C, Wei X, Swasey CH, Joetham A, Zarini S, Lively T, Takeda K, Loader J, Miyahara N, Kodama T, et al: Mast cells, Fc epsilon RI, and IL-13 are required for development of airway hyperresponsiveness after aerosolized allergen exposure in the absence of adjuvant. J Immunol 172: 6398-6406, 2004.

4. Cockcroft DW and Davis BE: Mechanisms of airway hyperresponsiveness. J Allergy Clin Immunol 118: 551-559; quiz 560-561, 2006.

5. Asquith KL, Ramshaw HS, Hansbro PM, Beagley KW, Lopez AF and Foster PS: The IL-3/IL-5/GM-CSF common receptor plays a pivotal role in the regulation of Th2 immunity and allergic airway inflammation. J Immunol 180: 1199-1206, 2008.

6. Takatsu K and Nakajima H: IL-5 and eosinophilia. Curr Opin Immunol 20: 288-294, 2008.

7. Busse WW, Ring J, Huss-Marp J and Kahn JE: A review of treatment with mepolizumab, an anti-IL-5 mAb, in hypereosinophilic syndromes and asthma. J Allergy Clin Immunol 125: 803-813, 2010.

8. Corren J: Role of interleukin-13 in asthma. Curr Allergy Asthma Rep 13: 415-420, 2013.

9. de Vries JE: The role of IL-13 and its receptor in allergy and inflammatory responses. J Allergy Clin Immunol 102: 165-169, 1998.

10. McKenzie GJ, Emson CL, Bell SE, Anderson S, Fallon P, Zurawski G, Murray R, Grencis R and McKenzie AN: Impaired development of Th2 cells in IL-13-deficient mice. Immunity 9: 423-432, 1998.

11. Punnonen J, Aversa G, Cocks BG, McKenzie AN, Menon S, Zurawski G, de Waal Malefyt R and de Vries JE: Interleukin 13 induces interleukin 4-independent IgG4 and IgE synthesis and CD23 expression by human B cells. Proc Natl Acad Sci USA 90: 3730-3734, 1993.

12. Horie S, Okubo Y, Hossain M, Sato E, Nomura H, Koyama S, Suzuki J, Isobe M and Sekiguchi M: Interleukin-13 but not interleukin-4 prolongs eosinophil survival and induces eosinophil chemotaxis. Intern Med 36: 179-185, 1997.

13. Luttmann W, Knoechel B, Foerster M, Matthys H, Virchow JC $\mathrm{Jr}$ and Kroegel C: Activation of human eosinophils by IL-13. Induction of CD69 surface antigen, its relationship to messenger RNA expression, and promotion of cellular viability. J Immunol 157: 1678-1683, 1996.

14. Kondo M, Tamaoki J, Takeyama K, Isono K, Kawatani K, Izumo T and Nagai A: Elimination of IL-13 reverses established goblet cell metaplasia into ciliated epithelia in airway epithelial cell culture. Allergol Int 55: 329-336, 2006.

15. Bossé Y, Thompson C, Audette K, Stankova J and Rola-Pleszczynski M: Interleukin-4 and interleukin-13 enhance human bronchial smooth muscle cell proliferation. Int Arch Allergy Immunol 146: 138-148, 2008.
16. Chiba Y, Nakazawa S, Todoroki M, Shinozaki K, Sakai H and Misawa M: Interleukin-13 augments bronchial smooth muscle contractility with an up-regulation of RhoA protein. Am J Respir Cell Mol Biol 40: 159-167, 2009.

17. Hacha J, Tomlinson K, Maertens L, Paulissen G, Rocks N, Foidart JM, Noel A, Palframan R, Gueders M and Cataldo DD: Nebulized anti-IL-13 monoclonal antibody Fab' fragment reduces allergen-induced asthma. Am J Respir Cell Mol Biol 47: 709-717, 2012.

18. Dittrich AM, Erbacher A, Specht S, Diesner F, Krokowski M, Avagyan A, Stock P, Ahrens B, Hoffmann WH, Hoerauf A and Hamelmann E: Helminth infection with Litomosoides sigmodontis induces regulatory $\mathrm{T}$ cells and inhibits allergic sensitization, airway inflammation, and hyperreactivity in a murine asthma model. J Immunol 180: 1792-1799, 2008.

19. Forsythe P, Inman MD and Bienenstock J: Oral treatment with live Lactobacillus reuteri inhibits the allergic airway response in mice. Am J Respir Crit Care Med 175: 561-569, 2007.

20. Karimi K, Inman MD, Bienenstock J and Forsythe P: Lactobacillus reuteri-induced regulatory $\mathrm{T}$ cells protect against an allergic airway response in mice. Am J Respir Crit Care Med 179: 186-193, 2009.

21. Liu J, Tran V, Leung AS, Alexander DC and Zhu B: BCG vaccines: Their mechanisms of attenuation and impact on safety and protective efficacy. Hum Vaccin 5: 70-78, 2009.

22. Li C, Xu Y, Zhang Z, Yang D, Liu X and Xiong W: An experimental study of the effect of bacille calmette-guerin vaccine on the production of a rat asthmatic model and its relation with gamma delta $\mathrm{T}$ cells. Zhonghua Jie $\mathrm{He} \mathrm{He} \mathrm{Hu} \mathrm{Xi} Z \mathrm{Za}$ Zhi 25: 162-165, 2002 (In Chinese).

23. Zhang J, Li C and Guo S: Effects of inhaled inactivated Mycobacterium phlei on airway inflammation in mouse asthmatic models. J Aerosol Med Pulm Drug Deliv 25: 96-103, 2012.

24. Kanehiro A, Lahn M, Mäkelä MJ, Dakhama A, Fujita M, Joetham A, Mason RJ, Born W and Gelfand EW: Tumor necrosis factor-alpha negatively regulates airway hyperresponsiveness through gamma-delta T cells. Am J Respir Crit Care Med 164: 2229-2238, 2001

25. Hopfenspirger MT and Agrawal DK: Airway hyperresponsiveness, late allergic response, and eosinophilia are reversed with mycobacterial antigens in ovalbumin-presensitized mice. J Immunol 168: 2516-2522, 2002.

26. Bradley BL, Azzawi M, Jacobson M, Assoufi B, Collins JV, Irani AM, Schwartz LB, Durham SR, Jeffery PK and Kay AB: Eosinophils, T-lymphocytes, mast cells, neutrophils, and macrophages in bronchial biopsy specimens from atopic subjects with asthma: Comparison with biopsy specimens from atopic subjects without asthma and normal control subjects and relationship to bronchial hyperresponsiveness. J Allergy Clin Immunol 88: 661-674, 1991 .

27. Jo EJ, Kim MY, Lee SE, Lee SY, Kim MH, Song WJ, Kim SH, Kang HR, Chang YS, Cho SH and Min KU: Eosinophilic airway inflammation and airway hyperresponsiveness according to aeroallergen sensitization pattern in patients with lower airway symptoms. Allergy Asthma Immunol Res 6: 39-46, 2014.

28. Yang MS, Lee HS, Kim MH, Song WJ, Kim TW, Kwon JW, Kim SH, Park HW, Chang YS, Cho SH and Min KU: Rhinitis patients with sputum eosinophilia show decreased lung function in the absence of airway hyperresponsiveness. Allergy Asthma Immunol Res 5: 232-238, 2013

29. Stein ML and Munitz A: Targeting interleukin (IL) 5 for asthma and hypereosinophilic diseases. Recent Pat Inflamm Allergy Drug Discov 4: 201-209, 2010.

30. Losol P, Kim SH, Hwang EK, Shin YS and Park HS: IL-5 promoter polymorphism enhances IgE responses to staphylococcal superantigens in adult asthmatics. Allergy Asthma Immunol Res 5: 106-109, 2013.

31. Jayaprakasam B, Yang N, Wen MC, Wang R, Goldfarb J, Sampson H and Li XM: Constituents of the anti-asthma herbal formula ASHMI(TM) synergistically inhibit IL-4 and IL-5 secretion by murine Th 2 memory cells, and eotaxin by human lung fibroblasts in vitro. J Integr Med 11: 195-205, 2013.

32. Seys SF, Grabowski M, Adriaensen W, Decraene A, Dilissen E, Vanoirbeek JA, Dupont LJ, Ceuppens JL and Bullens DM: Sputum cytokine mapping reveals an 'IL-5, IL-17A, IL-25-high' pattern associated with poorly controlled asthma. Clin Exp Allergy 43: 1009-1017, 2013.

33. Hussain S: IL-13 gene polymorphisms and their association with atopic asthma and rhinitis in Pakistani patients. Iran J Allergy Asthma Immunol 13: 298-299, 2014. 
34. Utsumi Y, Sasaki N, Nagashima H, Suzuki N, Nakamura Y, Yamashita M, Kobayashi $\mathrm{H}$ and Yamauchi K: Association of IL-13 gene polymorphisms with airway hyperresponsiveness in a Japanese adult asthmatic population. Respir Investig 51: 147-152, 2013.

35. Haldar P, Brightling CE, Hargadon B, Gupta S, Monteiro W, Sousa A, Marshall RP, Bradding P, Green RH, Wardlaw AJ and Pavord ID: Mepolizumab and exacerbations of refractory eosinophilic asthma. N Engl J Med 360: 973-984, 2009.

36. Pavord ID, Korn S, Howarth P, Bleecker ER, Buhl R, Keene ON, Ortega $\mathrm{H}$ and Chanez P: Mepolizumab for severe eosinophilic asthma (DREAM): A multicentre, double-blind, placebo-controlled trial. Lancet 380: 651-659, 2012.

37. Nair P, Pizzichini MM, Kjarsgaard M, Inman MD, Efthimiadis A, Pizzichini E, Hargreave FE and O'Byrne PM: Mepolizumab for prednisone-dependent asthma with sputum eosinophilia. N Engl J Med 360: 985-993, 2009.

38. Castro M, Mathur S, Hargreave F, Boulet LP, Xie F, Young J, Wilkins HJ, Henkel T and Nair P; Res-5-0010 Study Group: Reslizumab for poorly controlled, eosinophilic asthma: A randomized, placebo-controlled study. Am J Respir Crit Care Med 184: 1125-1132, 2011.

39. Wang Y and McCusker CT: Interleukin-13-dependent bronchial hyper-responsiveness following isolated upper-airway allergen challenge in a murine model of allergic rhinitis and asthma. Clin Exp Allergy 35: 1104-1111, 2005.

40. Hashimoto S and Bel EH: Targeting IL-5 in severe asthma: A DREAM come true? Lancet 380: 626-627, 2012.

41. Mathur M, Herrmann K, Li X, Qin Y, Weinstock J, Elliott D, Monahan J and Padrid P: TRFK-5 reverses established airway eosinophilia but not established hyperresponsiveness in a murine model of chronic asthma. Am J Respir Crit Care Med 159: 580-587, 1999.

42. Leckie MJ, ten Brinke A, Khan J, Diamant Z, O'Connor BJ, Walls CM, Mathur AK, Cowley HC, Chung KF, Djukanovic R, et al: Effects of an interleukin-5 blocking monoclonal antibody on eosinophils, airway hyper-responsiveness and the late asthmatic response. Lancet 356: 2144-2148, 2000.

43. El-Zein M, Parent ME, Benedetti A and Rousseau MC: Does BCG vaccination protect against the development of childhood asthma? A systematic review and meta-analysis of epidemiological studies. Int J Epidemiol 39: 469-486, 2010.

44. Obihara CC, Bollen CW, Beyers N and Kimpen JL: Mycobacterial infection and atopy in childhood: A systematic review. Pediatr Allergy Immunol 18: 551-559, 2007.

45. Hopfenspirger MT, Parr SK, Hopp RJ, Townley RG and Agrawal DK: Mycobacterial antigens attenuate late phase response, airway hyperresponsiveness, and bronchoalveolar lavage eosinophilia in a mouse model of bronchial asthma. Int Immunopharmacol 1: 1743-1751, 2001.

46. Assa'ad AH, Gupta SK, Collins MH, Thomson M, Heath AT, Smith DA, Perschy TL, Jurgensen CH, Ortega HG and Aceves SS: An antibody against IL-5 reduces numbers of esophageal intraepithelial eosinophils in children with eosinophilic esophagitis. Gastroenterology 141: 1593-1604, 2011.
47. Spergel JM, Rothenberg ME, Collins MH, Furuta GT, Markowitz JE, Fuchs G III, O'Gorman MA, Abonia JP, Young J, Henkel T, et al: Reslizumab in children and adolescents with eosinophilic esophagitis: Results of a double-blind, randomized, placebo-controlled trial. J Allergy Clin Immunol 129: 456-463, 463.e1-3, 2012.

48. Assa'ad AH and Rothenberg ME: Eosinophilic asthma: Insights into the effects of reducing IL-5 receptor-positive cell levels. J Allergy Clin Immunol 132: 1097-1098, 2013.

49. Akira S: Pathogen recognition by innate immunity and its signaling. Proc Jpn Acad Ser B Phys Biol Sci 85: 143-156, 2009.

50. Reba SM, Li Q, Onwuzulike S, Ding X, Karim AF, Hernandez Y, Fulton SA, Harding CV, Lancioni CL, Nagy N, et al: TLR2 engagement on CD4(+) T cells enhances effector functions and protective responses to Mycobacterium tuberculosis. Eur J Immunol 44: 1410-1421, 2014.

51. Almeida PE, Roque NR, Magalhães KG, Mattos KA, Teixeira L, Maya-Monteiro C, Almeida CJ, Castro-Faria-Neto HC, Ryffel B, Quesniaux VF and Bozza PT: Differential TLR2 downstream signaling regulates lipid metabolism and cytokine production triggered by Mycobacterium bovis BCG infection. Biochim Biophys Acta 1841: 97-107, 2014.

52. Chávez-Galán L, Ramon-Luing LA, Torre-Bouscoulet L, Pérez-Padilla R and Sada-Ovalle I: Pre-exposure of Mycobacterium tuberculosis-infected macrophages to crystalline silica impairs control of bacterial growth by deregulating the balance between apoptosis and necrosis. PLoS One 8: e80971, 2013.

53. Akdis CA, Kussebi F, Pulendran B, Akdis M, Lauener RP, Schmidt-Weber CB, Klunker S, Isitmangil G, Hansjee N, Wynn TA, et al: Inhibition of T helper 2-type responses, IgE production and eosinophilia by synthetic lipopeptides. Eur J Immunol 33: 2717-2726, 2003.

54. Manicassamy S and Pulendran B: Modulation of adaptive immunity with Toll-like receptors. Semin Immunol 21: 185-193, 2009.

55. Samary Cdos S, Antunes MA, Silva JD, Silva AL, Araujo CC, Bakker-Abreu I, Diaz BL, Fernezlian S, Parra ER, Capelozzi VL, et al: Impact of bacillus Calmette-Guerin Moreau vaccine on lung remodeling in experimental asthma. Respir Physiol Neurobiol 189: 614-623, 2013.

56. Czerkinsky C, Anjuere F, McGhee JR, George-Chandy A, Holmgren J, Kieny MP,Fujiyashi K, Mestecky JF,Pierrefite-Carle V, Rask C and Sun JB: Mucosal immunity and tolerance: Relevance to vaccine development. Immunol Rev 170: 197-222, 1999.

57. Horner AA and Raz E: Immunostimulatory sequence oligodeoxynucleotide: A novel mucosal adjuvant. Clin Immunol 95 (Suppl): S19-S29, 2000.

58. Horner AA, Datta SK, Takabayashi K, Belyakov IM, Hayashi T, Cinman N, Nguyen MD, Van Uden JH, Berzofsky JA, Richman DD and Raz E: Immunostimulatory DNA-based vaccines elicit multifaceted immune responses against HIV at systemic and mucosal sites. J Immunol 167: 1584-1591, 2001.

59. Takabayashi K, Libet L, Chisholm D, Zubeldia J and Horner AA: Intranasal immunotherapy is more effective than intradermal immunotherapy for the induction of airway allergen tolerance in Th2-sensitized mice. J Immunol 170: 3898-3905, 2003. 